\title{
A IDENTIFICAÇÃO DOS ESTILOS DE ENSINO DOS PROFESSORES DAS ARTES MARCIAIS CHINESAS (WUSHU) NO BRASIL
}

\author{
Marcelo Moreira Antunes \\ Centro Universitário da Cidade, Rio de Janeiro, Rio de Janeiro, Brasil
}

\section{Diego Luz Moura}

Centro Universitário da Cidade, Rio de Janeiro, Rio de Janeiro, Brasil

\begin{abstract}
Resumo
O estudo objetivou a identificação dos estilos de ensino de professores de wushu no Brasil. Foi construído um questionário baseado na teoria dos estilos de ensino de Mosston (1966). O instrumento foi respondido por 91 informantes presentes no XVII Campeonato Brasileiro de Kungfu/Wushu na cidade de Belo Horizonte em 2006. Os informantes eram originários de 16 diferentes estados brasileiros. Também se pretendeu identificar os estilos de ensino dos professores que, originariamente, ensinaram o wushu aos informantes do estudo. Os resultados apontaram uma prevalência do estilo 'Tarefa' demonstrando uma concepção mais fechada por parte dos informantes. Essa tendência também se verificou entre os professores dos informantes do estudo, porém de forma mais acentuada.
\end{abstract}

Palavras-chave: Wushu - Kungfu - Estilos de Ensino

\section{Introdução}

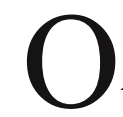

ensino da Educação Física é uma área de intenso debate. Entretanto, a maior parte desta produção está voltada para a intervenção na escola. É possível observar uma série de obras discutindo questões de cunho filosófico, pedagógico e social sobre os valores e o potencial educativo na formação do cidadão.

Neste contexto, poucas obras se reportaram especificamente ao ensino dos esportes, quer seja no âmbito escolar ou fora dele. Inicialmente, existiam os manuais de ensino que ofereciam repertório de atividades, chamadas "educativos", que tinham como objetivo indicar uma progressão de exercícios sobre os fundamentos da modalidade esportiva específica. Porém, com o surgimento do movimento crítico da Educação Física da década de 1980, boa parte deste material sucumbiu e foi esquecido por ser considerado "receita de bolo". Os conteúdos desses manuais ofereciam apenas procedimentos de ação e não 
promoviam reflexões sobre o esporte. Este panorama criou o que se considerou um entrave no ensino do esporte pela falta de material didático que contemplasse as demandas dessa nova perspectiva do ensino do esporte.

Todavia, devemos apontar alguns estudiosos que indiretamente apresentaram algumas reflexões sobre o ensino do esporte e acabaram preenchendo esta lacuna. Hildebrant e Langing (1986) destacaram alguns pressupostos para o ensino aberto do esporte. Segundo os autores, o ensino aberto baseia-se na ideia de propiciar ao aluno possibilidades de decidir sobre as atividades e estratégias de ensino. $\mathrm{O}$ ensino da Educação Física deve capacitar os alunos a tratar de tal modo os conteúdos esportivos nas mais diversas condições dentro e fora da escola, possibilitando-lhes condições de criar, no presente ou no futuro, sozinhos ou em conjunto, situações esportivas de modo crítico, determinadas autonomamente ou em conjunto. De modo geral, para Hildebrant e Langing (1986) o ensino dos esportes deve-se pautar em um processo de codecisão entre alunos e professor. Taffarel (1985), com base em modelos alemães de ensino do esporte, sugeriu algumas estratégias de ensino para as aulas de Educação Física que tinham como principal objetivo a estimulação da criatividade por meio de atividades recreativas e esportivas. Atualmente podemos verificar o surgimento de grupos que discutem o ensino do esporte com destaque a autores portugueses. Sobre o título de pedagogia dos esportes temos uma série de estudiosos procurando investigar métodos e estratégias de ensino, o que demonstra que esta área de estudos vem ocupando a atenção de pesquisadores. $\mathrm{Na}$ área do ensino das artes marciais diversos autores têm se dedicado a estudar o tema como os de Gomes et al (2010) e Del'Vecchio e Franchini (2006), e em nível internacional Kozub e Kozub (2004), Na (2009), entre outros.

Dentre as classificações sobre as metodologias de ensino dos esportes, identifica-se no espectro de estilos de ensino de Mosston (1966), material pioneiro, quer seja pela data de construção, quer seja pelo fato de ter sido construído especificamente para aulas de Educação Física, referência de destaque para o estudo do ensino das atividades físicas. Os estilos de ensino de Mosston (1966) constituem-se como teoria que analisa a estrutura de tomada de decisões em um comportamento de ensino e suas conexões. O espectro se divide em seis estilos de ensino: a) comandos, b) tarefas, c) avaliação recíproca, 
d) programação individualizada, e) descoberta orientada e f) solução de problemas.

O presente estudo tem como objetivo identificar a autorrepresentação dos estilos de ensino dos professores de wushu que atuam no Brasil. Para isso foi desenvolvido um instrumento de coleta de dados composto de duas partes. A primeira parte tem a função de caracterizar o professor, sua formação acadêmica e sua atividade no wushu. A segunda visou identificar os estilos de ensino das aulas do informante e do seu professor.

\section{O wushu no Brasil}

O ensino de modalidades esportivas no Brasil se deu principalmente na forma de comando e tarefa. Apesar de diversos pesquisadores discutirem sobre os estilos de ensino na Educação Física e nos esportes, o que se pode verificar na prática é a predominância de concepções mais fechadas de ensino nas práticas voltadas para a competição e para o alto rendimento. No contexto dos esportes com enfoque competitivo, inserem-se também as artes marciais ensinadas no Brasil.

As artes marciais começaram sua introdução no Brasil a partir da década de 1920 com a vinda dos primeiros japoneses para o Brasil, sendo o judô e o jujutsu as primeiras modalidades apresentadas por esses aos brasileiros. A reboque da imigração dos povos do extremo oriente para o Brasil, principalmente ao final da Segunda Grande Guerra, diversas outras artes marciais se instalaram em território nacional. No final da década de 1950, o wushu ${ }^{1}$ foi introduzido no Brasil estabelecendo-se inicialmente na cidade de São Paulo.

O ensino do wushu no Brasil, em primeiro momento, foi realizado pelos grandes mestres que se instalaram em São Paulo, em seguida no Rio de Janeiro e posteriormente em outros estados. Eles ensinaram essa arte marcial dentro de suas comunidades de compatriotas e depois

1-Wushu será usado no presente texto em substituição ao termo kungfu (comumente conhecido para designar as artes marciais chinesas), entende-se mais adequado utilizar a romanização padrão Pinyin aceita pela UNESCO para termos em chinês para este artigo. Em seu sentido original gongfu (kungfu) significa 'experiência alcançada com muito tempo de prática', por tanto pode ser aplicada a qualquer ofício e não representa as artes marciais chinesas, ao contrário de wushu que literalmente quer dizer arte marcial, ou ainda, arte da guerra. 
começaram a ensiná-la também a brasileiros natos. Desde sua introdução no país, até os dias atuais, o wushu se tornou difundido e ensinado na maior parte do território nacional, sendo representado oficialmente em 21 estados, segundo listagem das federações filiadas, disponível no site oficial da Confederação Brasileira de Kungfu Wushu (CBKW).

O wushu é ensinado no Brasil como atividade cultural, de lazer, de manutenção da saúde e ainda como esporte de alto rendimento. Segundo DaCosta (2006), estima-se que o total de praticantes em nosso país seja de cerca de 230 mil pessoas. Gradativamente, o wushu se tornou uma modalidade de atividade física amplamente aceita pelos brasileiros. Ainda, de acordo com DaCosta (2006), as modalidades de luta se apresentam distribuídas desta forma no Brasil: a) esgrima - 5 mil, b) boxe - 5 mil e 800, c) judô 200 mil, d) brazilian jiu-jitsu - 350 mil, e) karatê - 800 mil, f) capoeira - 6 milhões. Esses dados destacam a relevância das lutas e artes marciais em nosso país e demonstram a importância de se proceder a um estudo dos estilos de ensino utilizados pelos professores, instrutores e técnicos que lecionam artes marciais, em especial do wushu no Brasil. É relevante ressaltar que além da grande disseminação da prática das modalidades de luta no Brasil justificar um estudo dessa natureza, a carência de trabalhos científicos na área é um fato que, segundo Correia e Franchini (2010), reforça essa necessidade.

\section{Estilos de ensino de Mosston (1966)}

Segundo Moura (2009), o espectro de estilos de ensino Mosston $\left(1966^{2}\right)$ foi construído a partir do relacionamento entre professor e aluno, apresentando a perspectiva de "não-versus", ou seja, nenhum estilo de ensino, por si só, é melhor ou pior que o outro. Segundo Mosston, os estilos de ensino baseiam-se na tomada de decisões, relacionada com as fases de planejamento, orientação e controle de aprendizagem.

É importante ressaltar que, na prática, muitos estilos de ensino podem coexistir, sendo difícil encontrar uma aplicação integral dos estilos enfatizados no espectro.

2-Os estilos de ensino de Mosston (1966) são classificados em seis tipos e com o decorrer do tempo foram incorporados ao espectro mais quatro, entretanto nesta pesquisa optamos pela primeira classificação. 
Estilo de ensino por comandos

É o primeiro estilo de ensino do espectro de Mosston. Do ponto de vista pedagógico, esse estilo é considerado, hoje em dia, ligado ao modelo tradicional de educação e de inspiração militarista. Nesse estilo de ensino, o professor geralmente determina os objetivos da aula, escolhe as atividades, fornece as indicações precisas sobre o que executa. A metodologia baseia-se, sobretudo, na utilização de situações didáticas que dão margem apenas uma resposta, onde o comando precede cada movimento, que deve ser executado de acordo com um modelo padrão, cabendo, então, uma avaliação apenas no domínio motor. A relação entre professor e aluno se encontra em nível altamente elevado de formalismo, negando o diálogo.

Estilo de ensino por tarefas

No estilo de ensino por tarefas, o professor encontra-se no centro do processo selecionando os objetivos, as estratégias e determinando as formas de organização. Algumas decisões passam para os alunos, como a escolha das tarefas realizadas, bem como a de seu início e término, e dos padrões de desempenho. A avaliação é realizada de acordo com os critérios adotados pelos próprios alunos. A metodologia consiste em conteúdos apresentados aos alunos sob forma de tarefas divida por estações. A relação entre professor e aluno ainda apresenta certo grau de formalismo.

Estilo de ensino por avaliação recíproca

Neste estilo, o professor tem ainda papel predominante no processo, pois é ele quem escolhe os objetivos, seleciona as estratégias e impõe a organização. Entretanto, delega aos alunos a avaliação da aprendizagem, embora estabeleça critérios para sua realização. A metodologia consiste em fornecer aos alunos critérios para avaliar o desempenho dos colegas. A avaliação de aprendizagem é realizada em duplas, segundo os critérios do professor. A relação entre professor e aluno é ainda eivada de certo grau de formalismo.

Estilo de ensino por programação individualizada

Este estilo baseia-se no principio do trabalho individualizado. Ne- 
le o professor está no centro do processo com liberdade para dar mais atenção aos trabalhos individualmente e acompanhar a aprendizagem dos alunos. Estes trabalham em ritmo próprio desenvolvendo o senso de responsabilidade e iniciativa, aprendendo a avaliar-se. A metodologia baseia-se na existência das diferenças individuais, a adoção deste estilo permite atender aos alunos que necessitam de cuidados especiais. A avaliação de aprendizagem é realizada pelo professor de acordo com o desempenho individual. A relação entre professor e aluno é bastante informal.

Estilo de ensino por descoberta orientada

Neste estilo, o professor começa a deslocar-se do centro do processo em contraponto aos estilos precedentes, e assume o papel de elemento incentivador, orientador das atividades dos alunos, auxiliando-os e esclarecendo-os. A metodologia considera que a questão problematizadora produz a necessidade da busca de solução. Desta forma, o professor realiza perguntas, de maneira gradual que ocasionem uma série de respostas, que levem o educando à descoberta. Neste ensino, as avaliações e retificações de aprendizagem são realizadas por provocações de perguntas. A relação entre professor e aluno possui grande dose de informalismo, possibilitando a troca de informações.

Estilo de ensino por solução de problemas

No estilo o aluno é colocado verdadeiramente no centro do processo educativo passando a ser elemento ativo, formulando problemas, buscando respostas para as inquietações formuladas durante a aula. A metodologia consiste no princípio que aprender é resolver problemas. A estratégia parte de uma situação apresentada pelo professor e/ou aluno, que aguce a curiosidade dos educandos. Com base nesta situação, são definidos os objetivos e formulados operacionalmente. A seguir é elaborada uma situação problema cuja solução implicará precisamente na busca expressa no objetivo. As avaliações de aprendizagem são realizadas através de autoavaliações. A relação entre professor e aluno se encontra de maneira informal, em clima de descontração. 


\section{Materiais e métodos}

Esse estudo se caracteriza como pesquisa de campo, de caráter exploratório que, como ressalta Gil (2002), tem como objetivo de tornar mais claro o objeto pesquisado de modo a lançar luz sobre uma área. O procedimento de coleta de dados se realizou durante o XVII Campeonato Brasileiro de Kungfu / Wushu na cidade de Belo Horizonte no período de 6 a 10 de setembro de 2006, quando foi distribuído o instrumento de coleta de dados para os professores presentes no evento, e que se dispuseram voluntariamente a participar do estudo. A distribuição dos questionários aos professores se deu durante a chegada das delegações estaduais ao evento no dia 6 de setembro no momento em que eles estavam fazendo seu check in no evento. Os questionários respondidos foram recolhidos entre os dias 9 e 10, durante as cerimônias de premiação e entrega de homenagens.

A metodologia utilizada para a análise dos dados coletados no estudo foi de tratamento estatístico de característica descritiva, sedimentado no percentual de cada fator interferente identificado. Desta forma, indicando-se a tendência específica de estilo de ensino para os professores informantes e as tendências dos seus professores. Analisaram-se também as relações significativas entre os estilos de ensino e as características diversas dos informantes, tais como idade, tempo de prática e região onde ensinam.

\section{População e amostra}

A população do estudo foi compreendida por 133 professores que compareceram do XVII Campeonato Brasileiro de Kungfu / Wushu de 2006. A amostra abrangeu todos os professores presentes que ensinam estilos de wushu mapeados durante os anos de 2005 e 2006, perfazendo um número de 91 professores. Este critério foi adotado a partir do estudo realizado por Mendonça ${ }^{3}$ (2006), que identificou todos os esti$\operatorname{los}^{4}$ de wushu ensinados no Brasil, filiados às suas respectivas federações estaduais, e que possuem documentação oficial comprovando sua origem na China. Cabe ainda esclarecer que todos os informantes assinaram o Termo de Livre consentimento, e que participaram do estudo como informante voluntariamente. Este critério delimitou a amostra a 61 questionários válidos dos 91 respondidos.

Entende-se que essa divisão é importante, pois os estilos modernos 
foram criados com o objetivo de performance esportiva, com concepções didáticas mais atualizadas e critérios de padronização objetivando competições esportivas, e ainda representam apenas $18,4 \%$ do todo pesquisado ${ }^{5}$. Os estilos tradicionais, entretanto visavam o treinamento para a defesa e o ataque, e tinham por finalidade a sobrevivência, seja do indivíduo ou do grupo social específico. Os estilos tradicionais constituem a modalidade mais difundida, por terem sido os primeiros a serem ensinados no Brasil e por formarem a maior parcela dos professores pesquisados, representando $81,6 \%$ dos questionários válidos.

\section{Instrumento de coleta de dados}

O instrumento utilizado para a coleta de dados do presente estudo foi um questionário adaptado de Moura (2009) que foi dividido em duas partes. A primeira parte compõe-se de itens que caracterizam o informante quanto ao seu estado de origem, local onde aprendeu a modalidade, estilo que ensina, escolaridade, tempo de prática e de ensino do wushu. A segunda é composta de três colunas, das quais a central contém seis itens, cada um deles é formado por pequeno texto adaptado de forma a representar um estilo de ensino baseado no espectro idealizado por Moston (1966). A coluna à direita é para que o informante marque ao lado do texto que mais represente a sua forma de ensinar. A coluna à esquerda é para marcar ao lado do texto que mais represente a forma de ensinar do professor do informante, aquele que lhe ensinou o wushu inicialmente.

O espectro dos estilos de ensino elaborado por Mosston (1966) é composto da seguinte forma: a) Comandos; b) Tarefas; c) Avaliação Recíproca; d) Programação Individualizada; e) Descoberta Orientada; f) Solução de Problemas. Estes estilos de ensino se desenvolvem de forma a apresentar uma concepção de ensino que vai da mais 'fechada' até a mais 'aberta'.

3-Professor Samuel Mendonça, docente da Faculdade de direito da PUC Campinas, doutor em filosofia da educação e diretor técnico de estilos tradicionais da Confederação Brasileira de Kungfu / Wushu.

4-Um estilo de wushu se caracteriza por diversos fatores, tais como localização, princípios filosóficos, aspectos culturais e ênfase na força muscular, mas compartilham da mesma origem e fundamentação (LIMA, 2000).

5-Número de questionários descartados por não fazerem parte dos estilos tradicionais, mas sim da modalidade moderna de competição do wushu. 
Os estilos de ensino utilizam características da prática pedagógica que englobam o processo, a metodologia, a avaliação da aprendizagem e a relação professor $x$ aluno. Cada item elencado no questionário contemplava essas características de forma a estabelecer o vínculo com um estilo de ensino próprio. Os itens dessa parte do questionário podiam ser marcados em duas colunas, a primeira relacionada às aulas do professor informante e a segunda relacionada às aulas do professor que ensinou wushu ao informante. Podia-se ainda marcar mais de um item em cada coluna, de modo a contemplar diversos dos estilos de ensino de cada ator do processo.

Cabe ressaltar que a construção do instrumento de coleta de dados seguiu os critérios de confiabilidade e validade expostos por Thomas e Nelson (2002) tais como e clareza nos procedimentos e descrição detalhada.

\section{Apresentação e discussão dos dados}

Os questionários distribuídos no XVII Campeonato Brasileiro de Kungfu / Wushu de 2006, foram divididos entre as delegações dos estados participantes, de acordo com o número de professores previamente apresentado, e entregues aos cuidados do chefe de cada delegação. Foram distribuídos 133 questionários e o número de questionários respondidos ficou dividido entre os 17 estados como demonstra a tabela 1 . 
Tabela 1: Distribuição dos questionários por Estado

\begin{tabular}{c|c|c|c|c}
\hline \multirow{2}{*}{ Estado } & \multicolumn{2}{|c|}{$\begin{array}{c}\text { No questionários } \\
\text { devolvidos }\end{array}$} & \multicolumn{2}{c}{$\begin{array}{c}\text { No de questionários } \\
\text { válidos }\end{array}$} \\
\cline { 2 - 5 } & Quant. & $\%$ & Quant. & $\%$ \\
\hline \hline AL & 4 & 4,3 & 4 & 6,5 \\
\hline AM & 3 & 3,2 & zero & zero \\
\hline BA & 3 & 3,2 & 3 & 4,9 \\
\hline CE & 7 & 7,6 & 7 & 11,5 \\
\hline DF & 1 & 1,0 & $z$ ero & zero \\
\hline ES & 3 & 3,2 & 2 & 3,3 \\
\hline GO & 2 & 2,1 & 1 & 1,6 \\
\hline MG & 16 & 17,6 & 12 & 19,7 \\
\hline MS & 2 & 2,1 & 2 & 3,3 \\
\hline MT & 7 & 7,6 & $z e r o$ & zero \\
\hline PB & 4 & 4,3 & 3 & 4,9 \\
\hline PE & 2 & 2,1 & 2 & 3,3 \\
\hline PI & 1 & 1,0 & 1 & 1,6 \\
\hline PR & 4 & 4,3 & 2 & 3,3 \\
\hline RJ & 9 & 9,8 & 6 & 9,8 \\
\hline RS & 5 & 5,4 & 4 & 6,5 \\
\hline SP & 18 & 19,8 & 12 & 19,7 \\
\hline Totais & 91 & 100 & 61 & 100 \\
\hline \hline
\end{tabular}

Do total de 91 questionários respondidos, foram selecionados 61 para efeito de estudo seguindo os critérios expostos anteriormente na apresentação da metodologia.

Nível de escolaridade e tempo de prática

O nível de escolaridade dos informantes demonstrou que a grande maioria deles $(49,2 \%)$ possuía apenas o ensino médio completo, na época da coleta de dados. Aqueles com nível superior completo e incompleto representaram $11,5 \%$ e $13,1 \%$, respectivamente. Os informantes graduados em educação física representam $6,5 \%$ do grupo pesquisado. Em nível de pós-graduação lato sensu, a amostra apresentou $6,5 \%$ dos informantes com essa formação. Já para os informantes com ensino médio incompleto obteve-se $4,9 \%$ da amostra, o mesmo percentual alcançado pelos que possuíam o ensino fundamental com- 
pleto. Em nível de pós-graduação stricto sensu apenas 3,2\% dos informantes se encontram nessa formação.

O número de informantes com formação acima do ensino médio é baixo em relação às demais formações, isso pode demonstrar certo desinteresse para com formação superior por não ser considerada essencial para o exercício do ensino em artes marciais. O que se pode aferir baseado no que é apresentado por Antunes (2009) é que os cursos de graduação em Educação Física, que são os que mais se aproximam da prática das artes marciais como atividade física, não oferecem formação específica em artes marciais que supra os conhecimentos aprendidos nas academias. Para esse autor, as disciplinas dos cursos de graduação em Educação Física que abordam as artes marciais são focadas em conteúdos técnicos, deixando de lado aspectos educacionais, socioculturais e éticos. Desta forma, elas distanciam-se dos conteúdos ensinados nas academias, o que causa uma lacuna entre a prática e a teoria preconizada pelos cursos de graduação em Educação Física.

Entre os informantes foi pesquisada a relação entre o tempo de prática do wushu e o tempo de ensino desta arte marcial, ou seja, o tempo necessário para que o praticante possa iniciar a ensinar o wushu. Identificou-se que a maior ocorrência (61\%) desta relação ficou estabelecida com intervalo entre quatro e nove anos do início da prática ao início da ação de ensinar o wushu. Em segundo lugar ficou o intervalo entre 10 a 17 anos (25,4\%), em terceiro lugar ficaram os informantes que praticaram até três anos $(13,6 \%)$ antes de iniciar suas atividades de ensino. Pode-se aferir que os intervalos abaixo de três anos demonstram que esses informantes tiveram pouca ou nenhuma vivência antes de iniciar as atividades de ensino, entretanto eles representam a minoria dos informantes. Por outro lado, os informantes com intervalos acima de dez anos demonstram que esse grupo possuía longa experiência antes de iniciar sua prática de ensino.

Os dados apontam que para se iniciar o ensino de artes marciais chinesas é necessário três anos de prática no mínimo, tempo próximo ao da duração do curso de licenciatura em Educação Física na atualidade. Entretanto, a pesquisa demonstra que a grande maioria $(86,4 \%)$ levou mais que quatro anos para iniciar as atividades de ensino dessa arte marcial. Tendo em vista o que é posto por Antunes (2009) no que se refere aos conteúdos ensinados nas academias de lutas e nos cursos de Educação Física, a formação no curso de graduação em Educação Física não fornece meios concretos de se ensinar as artes marciais em 
iguais condições de experiência por tempo de prática e por conteúdos aprendidos com os instrutores e professores formados apenas com a vivência prática das academias.

A questão da carga horária dedicada às disciplinas de lutas nos cursos de graduação em Educação Física também é tratada por Antunes (2009). O autor afirma que as disciplinas de lutas têm cargas horárias que variam entre 40 até 60 horas, e que não se aproximam da carga horária necessária para a formação de instrutores e professores de artes marciais nas academias. Desta forma, o tempo de formação que os informantes indicam em suas contribuições ao estudo aponta para uma carga horária muito superior a que é apresentada nas disciplinas correlatas nos cursos de Educação Física. Isso se verifica também em outras artes marciais além do wushu, como aponta Antunes (2009), quando afirma que o tempo necessário para se formar um professor de artes marciais varia de cinco a dez anos.

\section{Os estilos de ensino identificado pelos informantes}

Os estilos de ensino que mais ocorreram relacionados aos estados de origem dos informantes estão apresentados na Tabela 2 a seguir.

Tabela 2: Relações entre os estilos de ensino e os estados de origem dos informantes por região do Brasil

\begin{tabular}{|c|c|c|c|c|c|}
\hline REGIÃO & $\begin{array}{c}\mathbf{( \% )} \\
\text { Por } \\
\text { região }\end{array}$ & ESTILOS & $(\%)$ & $\mathrm{N}^{\circ}$ & ESTADOS \\
\hline \multirow{4}{*}{ Nordeste } & \multirow{4}{*}{33} & Tarefa & 65 & 13 & $\mathrm{BA}, \mathrm{CE}, \mathrm{PB}, \mathrm{PE}$ e PI \\
\hline & & Comando & 25 & 5 & $\mathrm{AL}$ e BA \\
\hline & & Avaliação recíproca & 5 & 1 & $\mathrm{CE}$ \\
\hline & & Outros & 5 & 1 & $\mathrm{CE}$ \\
\hline \multirow{2}{*}{$\begin{array}{l}\text { Centro- } \\
\text { oeste }\end{array}$} & \multirow[t]{2}{*}{5} & $\begin{array}{l}\text { Programação } \\
\text { individualizada }\end{array}$ & 66,7 & 2 & MS \\
\hline & & Tarefa & 33,3 & 1 & $\mathrm{GO}$ \\
\hline \multirow{5}{*}{ Sudeste } & \multirow{5}{*}{52} & Tarefa & 50 & 16 & ES, MG, RJ e SP \\
\hline & & Com ando & 25 & 8 & MG e SP \\
\hline & & Avaliação recíproca & 9,4 & 3 & MG e SP \\
\hline & & $\begin{array}{c}\text { Programação } \\
\text { individualizada }\end{array}$ & 9,4 & 3 & SP \\
\hline & & Solução de problema & 6,2 & 2 & MG \\
\hline \multirow[b]{2}{*}{ Sul } & \multirow[b]{2}{*}{10} & Tarefa & 50 & 3 & RS e PR \\
\hline & & $\begin{array}{c}\text { Programação } \\
\text { individualizada }\end{array}$ & 50 & 3 & RS e PR \\
\hline
\end{tabular}


Os resultados apresentados na Tabela 2 indicam que os informantes dos estados que mais apresentaram concepções de ensino 'fechado' foram os de Alagoas, com a totalidade das respostas centradas em Comando, e os do Rio de Janeiro, do Piauí, de Pernambuco, da Paraíba, do Espírito Santo e de Goiás tendo todas as respostas como 'Tarefa'. Já entre os informantes com concepções mais 'abertas' em suas práticas de ensino podem-se destacar os do Paraná e o do Rio Grande do Sul. Os demais informantes apresentam uma mescla de estilos de ensino, entretanto todos com predominância do estilo 'Tarefa'.

No total das respostas referentes à caracterização dos estilos de ensino, fornecidas pelos informantes sobre suas aulas de wushu, obtiveram-se características predominantes de 'Tarefa', com 54,1\%. A segunda maior ocorrência foi para 'Comando' com 21,3\% das respostas e a terceira maior ficou com 'Programação individualizada' representando $13,1 \%$ das respostas. A 'Avaliação recíproca', representou 6,5\% das ocorrências. A 'Soluções de Problemas' foi o estilo com menos ocorrências, apresentando-se com apenas 3,3\%. De modo geral, os dados da pesquisa apontam para uma característica predominantemente 'fechada' de ensino em relação ao processo ensino-aprendizagem do wushu, dando pouca ou nenhuma participação aos alunos no processo de tomada de decisão, caracterizando assim, o estilo de ensino do wushu, como 'Comando e Tarefa' principalmente.

Essa caracterização pode ser comparada com os resultados alcançados por Mosston e Ashworth (1990) e do estudo de Gozzi e Ruete (2006), nos quais se evidenciaram o estilo 'Tarefa' como predominante. A Tabela 2 apresenta as relações das respostas vinculadas aos estados aos quais pertencem os informantes e os estilos neles predominantes. No estudo de $\mathrm{Na}$ (2009) sobre os estilos de ensino de Mosston aplicados ao Taekwondo observa-se a prevalência do estilo comando, seguido de Avaliação recíproca e a autochecagem ${ }^{6}$. Na (2009) ainda afirma que o uso do estilo 'Comando' é útil para ensinar conteúdos não familiares para alunos ocidentais.

No que se refere aos estilos de ensino dos professores que ensinaram wushu aos informantes, as repostas indicaram que 32,2\% utilizaram o estilo 'Tarefa' para ensinar, 21,2\% representaram o estilo 'Comando', 18,8\% foram 'Avaliação recíproca', 12,2\% se caracterizou como 'Programação individualizada', 12,2\% para 'Descoberta

6-Estilo de ensino introduzido em trabalho recente de Mosston e Ashworth (2002). 
orientada' e por último 'Soluções de problemas' com 3,3\% das respostas. Esses dados demonstram que esses professores tinham concepções de ensino mais fechadas que seus alunos, indicando leve evolução dos estilos de ensino no sentido de se tornaram mais 'abertos'. Isso não representou, entretanto, aumento expressivo dos percentuais de estilos de ensino voltados para a autonomia dos alunos, prevalecendo sempre os mais centrados na ação do professor.

\section{Considerações finais}

No presente estudo pode-se verificar que há uma prevalência do estilo 'Tarefa' nas aulas de wushu de acordo com os informantes consultados.

Essa tendência para o estilo 'Tarefa' demonstra o avanço na direção do ensino que leva em consideração o aluno como centro do processo, apesar de o professor ainda deter todo o processo decisório. Este avanço evidencia a evolução de um processo militarizado de ensino das atividades físicas - estilo Comando - que predominava no ensino da Educação Física em seus primeiros momentos no Brasil para o estilo Tarefa.

Fica também evidente que a concepção dos informantes, em relação aos seus estilos de ensino do wushu no Brasil, assemelha-se ao encontrado em outros estudos. Entretanto, os informantes, que possuíam formação acadêmica superior em Educação Física, apresentaram tendência a concepções de ensino mais 'abertas', caracterizadas predominantemente por estilos de 'Programação individualizada'. Este fato pode estar indicando que a união dos conhecimentos do wushu com os procedimentos didáticos assimilados em cursos de graduação em Educação Física pode ter contribuído para tal comportamento.

Os informantes que possuíam formação superior em outras áreas diferentes da Educação Física tenderam a apresentar concepções mais 'fechadas' de ensino, predominantemente estilos 'Tarefa' e 'Comando'. Isso pode indicar que, para esses informantes, a graduação em nível superior não lhes garantiu a possibilidade de ensinar com estilos diferentes de seus professores. Em sua maioria, os informantes do estudo possuíam a formação no ensino médio e para grande parte deles o estilo 'Tarefa' se consolidou como proeminente.

As concepções 'fechadas' de ensino também se apresentaram presentes nos estilos de ensino dos que ensinaram o wushu para os infor- 
mantes do estudo (ou seja, os professores dos professores). Eles apresentaram predominantemente o estilo 'Tarefa', de forma mais frequente que no caso de seus alunos. Isso pode demonstrar uma pequena evolução no sentido de se abrir mais as concepções de ensino das gerações de professores subsequentes aos que iniciaram o ensino do wushu no Brasil.

Os estilos Solução de problemas e Programação individualizada apresentam baixa representatividade nas respostas dos informantes que participaram do estudo. Já o estilo Descoberta orientada não se fez representado entre as respostas dos informantes. Este quadro ressalta que os estilos de ensino que mais privilegiam os alunos no processo de tomada de decisão não são frequentemente contemplados no processo de ensino do wushu no Brasil. Isso reforça o fato de que as concepções fechadas de ensino ainda são predominantes para o ensino desta arte marcial.

Apesar do caráter 'fechado' das concepções de ensino ainda fazer parte das aulas de wushu no Brasil, devemos ter em perspectiva que essa arte marcial tem suas origens na necessidade de sobrevivência de um povo, dando enfoque principal à defesa e aos aspectos militares de suas atividades. Desta forma a concepção 'fechada' de ensino do wushu pode ser indicativa da remanescência dessas características culturais. Essas características de ensino, apesar de fazerem parte do arcabouço cultural do wushu, podem ser modificadas com a sua esportivização e mais profundamente com a possibilidade de sua inclusão em ambiente escolar como conteúdos da Educação Física curricular, ganhado contornos de uma dimensão esportiva e educacional. E como ressalta Tubino (2001) à medida que o esporte ou a atividade física amplia seus contornos sociais, possibilita o aumento da participação dessa mesma sociedade em suas práticas.

Identification of teachers teaching styles of Chinese martial artes (Wushu) in Brazil

\begin{abstract}
The study aimed to identify the teachers teaching styles of wushu in Brazil. A questionnaire was constructed based on the theory of teaching styles of Mosston (1966). Ninety-one informants present in the XVII Brazilian Championship of Kung Fu / Wushu in Belo Horizonte answered the instrument in 2006. Informants were from 16 different Brazilian states. It is also intended to identify the teaching styles of teachers who originally taught wushu to informants of the study. The results showed a prevalence of 'Task' style showing a more closed conception by the
\end{abstract}


informants. This trend was also found in the teachers of the informants of the study, but more steeply.

Keywords: Wushu - Kungfu - Teaching Styles

La identicación de los estilos de enseñanza de los profesores de artes marciales chinas (wushu) en Brasil

\section{Resumen}

El presente estudio objetivó la identificación de los estilos de enseñanza de los profesores de wushu en Brasil. Se construyó un instrumento de levantamiento de datos basado en la teoría de los estilos de enseñanza de Mosston (1966). El instrumento fue respondido por 91 profesores de wushu participantes del XVII Campeonato Brasileño de Kungfu/Wushu en Belo Horizonte, 2006. Esos profesores eran originarios de 16 estados brasileños diferentes. Se pretendió identificar los estilos de enseñanza de los profesores que, originalmente, enseñaron el wushu a los informantes del estudio. Los resultados apuntaron un predominio del estilo 'Tarea' demostrando una concepción mas cerrada por parte de los informantes. Esa tendencia también se verificó en los profesores de los informantes del estudio, pero de forma más marcado.

Palabras clave: Wushu - Kungfu - Estilos de Enseñanza

\section{Referências}

ANTUNES, M. M. A relação entre as artes marciais e lutas das academias e as disciplinas de lutas dos cursos de graduação em educação física. EFDeportes Revista Digital, Buenos Aires, Año 14, n. 139, Diciembre, 2009. Disponível em: <http://www.efdeportes.com/efd139/artes-marciais-e-lutas.htm>.

CONFEDERAÇÃO BRASILEIRA DE KUNGFU WUSHU. Filiadas. Disponível em: <www.cbkw.org.br>. Acesso em: 02 de abril de 2007 às 9:30.

CORREIA, W. R.; FRANCHINI, E. A produção acadêmica em lutas, artes marciais e esportes de combate. Motriz, Rio Claro, v. 16, n. 1, p. 1-9, jan./mar. 2010.

DACOSTA, Lamartine (org.). Atlas do esporte no Brasil. Rio de Janeiro: CONFEF, 2006.

FARIA JÚNIOR, A. G. et al. Prática de ensino em educação física: estágio supervisionado. Rio de Janeiro: Interamericana, 1982. 
DEL'VECCHIO, F.B.; FRANCHINI, E. Lutas, Artes Marciais e Esportes de Combate: Possibilidades, Experiências e Abordagens no currículo em Educação Física. In: SOUZA NETO, S.; HUNGER, D. (org.). Formação profissional em Educação Física: Estudos e Pesquisas, p.99-109, 2006.

GIL, A. C. Como elaborar projetos de pesquisa. 4 ed. São Paulo: Atlas, 2002.

GOMES, M. S. P.; MORATO, M. P.; DUARTE, E.; ALMEIDA, J. J. G. Ensino das lutas: dos princípios condicionais aos grupos situacionais. Movimento, Porto Alegre, v. 16, n. 02, abril/junho, 2010.

GOZZI, M. C. T.; RUETE, H. M. Identificando estilos de ensino em aulas de educação física em segmentos não escolares. Revista Mackenzie de Educação Física e Esporte, São Paulo, v.5, n. 1, p. 117-34, 2006.

HILDEBRANDT, R.; LAGING, R. Concepções abertas no ensino da educação física. Rio de Janeiro: Ao Livro Técnico, 1986.

KOZUB, F.M.; KOZUB, M.L. Teaching combative sports through tatics. Journal of Physical Education, Recreation, and Dance, Champagne, v.75, n.8, p.16-21, october, 2004.

LIMA, L. M. S. O tao da educação: a filosofia oriental na escola ocidental. São Paulo: Agora, 2000.

MENDONÇA, S. Mapeamento: Sistemas Mapeados no Brasil em 2005 e 2006. São Paulo: CBKW, 2006. Disponível em: $<$ www.cbkw.org.br $>$.

MOSSTON, M. Teaching physical education. Columbus: Merril Books, 1966.

MOSSTON, M.; ASHWORTH, S. Do comando à descoberta: a ciência e a arte do ensino. New York. Longman Publishers. (trad) KRUG, D.F. : UNICRUZ/FEFCA-RS, 1990.

. Teaching physical education. San Francisco: Benjamin Cummings, 2002. 
MOURA, D. L. A Educação Física Escolar e os estilos de ensino: uma análise de duas escolas do Rio de Janeiro. EFDeportes Revista Digital, Buenos Aires, Año 14, n. 137, Octubre, 2009. Disponível em: < http://www.efdeportes.com/efd137/a-educacao-fisica-escolar-e-os-estilos-de-ensino.htm>.

NA, J. Teaching taekwondo through Mosston's spectrum of styles: the spectrum offers flexibility in teaching various aspects of martial arts content. The Journal of Physical Education Recreation \& Dance, Champagne, v. 80, n. 2, february, 2009.

TAFFAREL, C. N. Z. Criatividade nas aulas de educação física. Rio de Janeiro: Ao Livro Técnico, 1985.

THOMAS, J. R. NELSON, J. K. Métodos de pesquisa em educação física. 3ed. Porto Alegre: Artmed, 2002.

TUBINO, M. J. G. Dimensões sociais do esporte. 2 ed. São Paulo: Cortez, 2001.

Recebido em: 17/03/2010

Revisado em: 08/09/2010

Aprovado em: 14/09/2010

Endereço para correspondência

lightdiego@yahooe.com.br

Diego Luz Moura

Centro Universitário da Cidade.

Rua Florianópolis, 1.296

Praça Seca

21321-050 - Rio de Janeiro, RJ - Brasil 